\section{Early response of retinal angiomatous proliferation treated with intravitreal pegaptanib: a retrospective review}

S Mahmood, N Kumar, PM Lenfestey, S Murjaneh, H Heimann and SP Harding
St Paul's Eye Unit, Royal Liverpool University Hospital, Liverpool, UK

\section{Correspondence:}

$S$ Mahmood, c/o Professor SP Harding, St Paul's Eye Unit, Royal Liverpool University Hospital,

Prescot Street, Liverpool L7 8XP, UK. Tel: + 0151706 3966; Fax: + 08701276460 . E-mail: saj@ eyebase.co.uk

Received: 10 December 2007

Accepted in revised form: 8 March 2008 Published online: 18 April 2008

\begin{abstract}
Aims To evaluate the early functional and anatomical responses to intravitreal pegaptanib in patients with retinal angiomatous proliferation (RAP).

Methods Retrospective review of consecutive patients newly diagnosed with RAP treated with intravitreal pegaptanib $(0.3 \mathrm{mg})$.

Examination at baseline and 12 weekly intervals included refraction protocol best corrected visual acuity (BCVA), fluorescein angiography (FA), and optical coherence tomography (OCT). At intervening 6 weekly visits a reduced protocol assessment included BCVA and OCT.

Results A total of 16 eyes of 16 patients (12 female, mean age 76.0 years) with RAP at baseline (15 stage 3 , one stage 2 ) were treated. One patient had poor response, losing 20 ETDRS letters after one injection and was switched to photodynamic therapy combined with intravitreal triamcinolone. Mean BCVA $(n=15)$ was baseline $45 \pm 11$ (mean \pm SD) letters, 12 weeks $43 \pm 14$ letters, 24 weeks $40 \pm 14$ letters; the reduction from baseline to 24 weeks was statistically significant $(P=0.04)$. Vision remained stable defined as \pm 15 letters of baseline BCVA in $13(87 \%)$ of patients $2(13 \%)$ lost $>15$ letters. Mean OCT central foveal thickness (CFT) $(n=13)$ was: baseline $325 \pm 123 \mu \mathrm{m}, 12$ weeks $343 \pm 130 \mu \mathrm{m}, 24$ weeks $321 \pm 115 \mu \mathrm{m}$; difference at 24 weeks was not statistically significant $(P=0.9)$. A pigment epithelial detachment was present in 12 cases; height was reduced in 10 cases at 24 weeks. Persistent leakage on FA was seen in $\mathbf{1 3}$ out of 15 cases at 24 weeks.

Conclusion Early results of treatment of RAP with intravitreal pegaptanib suggest some
\end{abstract}

stabilizing effect on this normally progressive disease.

Eye (2009) 23, 530-535; doi:10.1038/eye.2008.101; published online 18 April 2008

Keywords: pegaptanib; intravitreal; retinal angiomatous proliferation; macugen

\section{Introduction}

Retinal angiomatous proliferation (RAP) is a form of neovascular age-related macular degeneration (AMD) in which intraretinal neovascularisation (stage I) progresses to subretinal neovascularisation with or without serous pigment epithelial detachment (PED) (stage II), followed by choroidal neovascularisation (CNV) (stage III). ${ }^{1,2}$ It is estimated to comprise $10-15 \%$ of all newly diagnosed neovascular AMD and $30 \%$ of occult $\mathrm{CNV}^{3}$ The presence of RAP is correlated with worse visual prognosis ${ }^{3}$ and is commonly bilateral with nearly all patients developing RAP in the fellow eye within 3 years. ${ }^{4}$

Effective treatment for RAP has yet to be established. Thermal laser may have a role for extrafoveal stage I and II RAP ${ }^{5}$ but reported outcomes are poor in more advanced disease. ${ }^{6}$ Surgical ablation of feeder vessels has been described in a small number of patients with stage II $\mathrm{RAP}^{7}$ but appears ineffective with a high rate of recurrence. ${ }^{8}$ Case series of patients treated with anecortave acetate ${ }^{9}$ or photodynamic therapy (PDT) with verteporfin as monotherapy have not shown favourable functional or anatomical outcome. ${ }^{10}$ PDT has been applied more successfully when combined with intravitreal triamcinolone (IVTA) injected simultaneously or up to 14 days before or after. 
Case series with 12-month follow-up report $83-89 \%$ visual stabilisation and $35-37 \%$ visual improvement ${ }^{11-13}$ but with important side effects of raised intraocular pressure (IOP), cataract, and retinal pigment epithelial tears. $^{14,15}$

The intravitreal vascular endothelial growth factor (VEGF) antagonists ranibizumab and pegaptanib have been shown to reduce vascular leakage and improve the functional outcome in patients with $\mathrm{CNV}{ }^{16-18}$

Uncontrolled studies suggest that bevacizumab may also be effective. ${ }^{19,20}$ Outer retinal ischaemia with localised VEGF production has been postulated as a possible mechanism for the development of intraretinal neovascularisation in RAP. $^{2}$ Two case series have shown promising 3 month data on treatment of RAP with intravitreal bevacizumab. ${ }^{21,22}$ At the time of writing, there are no published reports of the effectiveness of ranibizumab or pegaptanib in the treatment of RAP. We report 6-month follow-up of a case series of patients with RAP treated with intravitreal pegaptanib.

\section{Materials and methods}

Retrospective analysis of a consecutive case series of patients diagnosed with RAP and treated with 6 weekly intravitreal pegaptanib at a regional tertiary referral treatment centre.

Examination at baseline and 12 weekly intervals included refraction protocol best corrected visual acuity (BCVA) measured by an optometrist and recorded as letters read at $2 \mathrm{~m}$ on ETDRS charts with standard illumination, IOP, and slit-lamp fundus biomicroscopy. Stereoscopic colour fundus photography, fluorescein angiography (FA), and optical coherence tomography (OCT) were also performed.

At intervening 6 weekly visits, a reduced protocol assessment included BCVA using the previous refraction, IOP, and OCT.

\section{Diagnosis of RAP}

Diagnosis was confirmed by two senior doctors (PML, $\mathrm{SM}$ ) with experience of grading colour photographs and angiograms within the UK Network of Reading Centres and classified according to the system proposed by Yannuzzi et al. ${ }^{2}$ The following features specific to the diagnosis and staging of RAP were required to include the patient in the study. With indocyanine green (ICG) angiography being performed in some cases to support the diagnosis.

1. Features on stereoscopic colour photographs:

- early lesions: intraretinal haemorrhage, feeder retinal vessels with right angle turns and dilated tips
- later lesions: serous pigment epithelial detachment (PED) and exudates

2. Features on stereoscopic angiography:

- small zone(s) of early intense hyperfluorescence ('hot

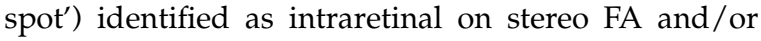
ICG showing leakage throughout the series

- feeder vessel from retinal circulation best seen on arteriovenous phase of dye transit phase, retina-retina anastomosis or chorioretinal anastomosis

- serous PED and evidence of CNV

Zeiss VISUPAC software was used to measure the greatest linear diameter (GLD) of the lesion, (RAP vessels and any associated serous or fibrovascular pigment epithelial detachment (FPED)).

OCT imaging was performed using the Stratus OCT3 system (Carl Zeiss, software version 4.0). The Fast Macular Thickness acquisition protocol was used and central foveal thickness (CFT) was recorded. Correct identification of the retinal boundaries by the software was verified.

All patients underwent an intravitreal injection with $0.3 \mathrm{mg}(0.09 \mathrm{ml})$ pegaptanib by pars plana under sterile conditions. Hand movement perception and pulsation of the central retinal artery were confirmed after injection. Patients were contacted by telephone 3 days after each injection to confirm there were no adverse reactions and scheduled for follow-up visits at 6-week intervals.

A paired $t$-test was performed for analysis of BCVA and retinal thickness over time. $P$-values $<0.05$ were considered statistically significant.

\section{Results}

A total of 16 eyes of 16 patients were treated, (summary data, Table 1). Twelve patients were female. The mean age was 76.0 years (range $58-87$ ). One eye was graded as RAP stage 2 , the remainder as stage 3 . Symptom duration before first treatment ranged from 12 to 68 weeks (median 25 weeks). In each of 13 cases, the fellow eyes had previously been affected by neovascular AMD and had poor visual acuity; six of these had one or more chorioretinal anastomosis. One patient had a poor response after the first injection with loss of 20 ETDRS letters and increased retinal thickness and was switched to PDT combined with IVTA (sample case 2). This patient was excluded from quantitative analysis at 24 weeks. Baseline OCT information was not available in two patients who had their first treatment in private sector hospitals where this was not performed as routine. Quantitative measures on FA was also not possible on baseline images for these patients but diagnosis could be confirmed. One patient did not have any follow-up 
angiography due to presumed allergy; diagnosis was made on referral angiogram. Fourteen patients received all four injections before their 24-week visit; one patient had only three injections as he failed to attend one appointment. All patients completed 24-week follow-up.
Mean BCVA $(n=15)$ was: baseline $45 \pm 11$ (mean \pm SD) letters, 12 weeks $43 \pm 14$ letters, 24 weeks $40 \pm 14$ letters; the reduction from baseline to 24 weeks was statistically significant $(P=0.04$ paired $t$-test). Vision remained stable defined as \pm 15 letters of baseline BCVA in 13 (87\%) of

Table 1 Summary patient data

\begin{tabular}{|c|c|c|c|c|c|c|c|c|c|c|c|c|}
\hline \multirow[t]{2}{*}{ Patient } & \multirow{2}{*}{$\begin{array}{l}\text { RAP } \\
\text { Stage }\end{array}$} & \multicolumn{4}{|c|}{ Baseline } & \multicolumn{2}{|c|}{12 weeks } & \multicolumn{4}{|c|}{24 weeks } & \multirow{2}{*}{$\begin{array}{l}\text { No. of } \\
\text { injections }\end{array}$} \\
\hline & & $\begin{array}{c}\text { Vision } \\
\text { (ETDRS } \\
\text { letters) }\end{array}$ & $\begin{array}{c}\text { OCT CFT } \\
(\mu m)\end{array}$ & $P E D$ & $\begin{array}{c}\text { Lesion } \\
\text { GLD } \\
(\mathrm{mm})\end{array}$ & $\begin{array}{c}\text { Vision } \\
\text { (ETDRS } \\
\text { letters) }\end{array}$ & $\begin{array}{c}\text { OCT CFT } \\
(\mu m)\end{array}$ & $\begin{array}{c}\text { Vision } \\
\text { (ETDRS } \\
\text { letters) }\end{array}$ & $\begin{array}{c}\text { OCT CFT } \\
(\mu m)\end{array}$ & $P E D$ & $\begin{array}{c}\text { Lesion } \\
\text { GLD }(\mathrm{mm})\end{array}$ & \\
\hline 1 & 2 & 63 & 258 & Yes & 1.99 & 69 & 263 & 68 & 242 & Reduced & 0.56 & 4 \\
\hline 2 & 3 & 36 & 232 & No & 7.35 & NA & NA & 22 & 281 & No & $\begin{array}{c}\text { FA not } \\
\text { performed }\end{array}$ & 3 \\
\hline 3 & 3 & 34 & 461 & Yes & NA & 29 & 572 & 31 & 511 & Stable & $\begin{array}{c}\text { FA not } \\
\text { performed }\end{array}$ & 4 \\
\hline 4 & 3 & 42 & 391 & Yes & 6.02 & 34 & 411 & 29 & 411 & Reduced & 5.84 & 4 \\
\hline 5 & 3 & 67 & 172 & Yes & 6.57 & 64 & 240 & 61 & 301 & Reduced & 6.6 & 4 \\
\hline 6 & 3 & 60 & 164 & Yes & 6.15 & 56 & 333 & 53 & 278 & Reduced & 5.25 & 4 \\
\hline 7 & 3 & 33 & 602 & Yes & 7.01 & 29 & 604 & 40 & 527 & Stable & 8.04 & 4 \\
\hline 8 & 3 & 50 & 358 & Yes & 2.27 & 57 & 295 & 48 & 285 & Reduced & 2.25 & 4 \\
\hline 10 & 3 & 44 & NA & No & NA & 43 & 203 & 44 & 272 & No & 4.03 & 4 \\
\hline 11 & 3 & 43 & 308 & Yes & 7.42 & 43 & 332 & 23 & 405 & Reduced & 7.19 & 4 \\
\hline 12 & 3 & 44 & 275 & Yes & 5.31 & 45 & 311 & 36 & 250 & Reduced & 4.71 & 4 \\
\hline 13 & 3 & 42 & NA & Yes & NA & 21 & 349 & 21 & 264 & Stable & 6.51 & 4 \\
\hline 14 & 3 & 44 & 337 & Yes & 5.49 & 59 & 202 & 54 & 132 & Reduced & 5.47 & 4 \\
\hline 15 & 3 & 42 & 245 & Yes & 6.24 & 40 & 201 & 41 & 204 & Reduced & 5.63 & 4 \\
\hline 16 & 3 & 63 & 399 & Yes & 4.58 & $43^{a}$ & $863^{a}$ & 61 & 238 & Reduced & 5.73 & 1 \\
\hline
\end{tabular}

$\mathrm{NA}=$ not available

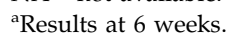
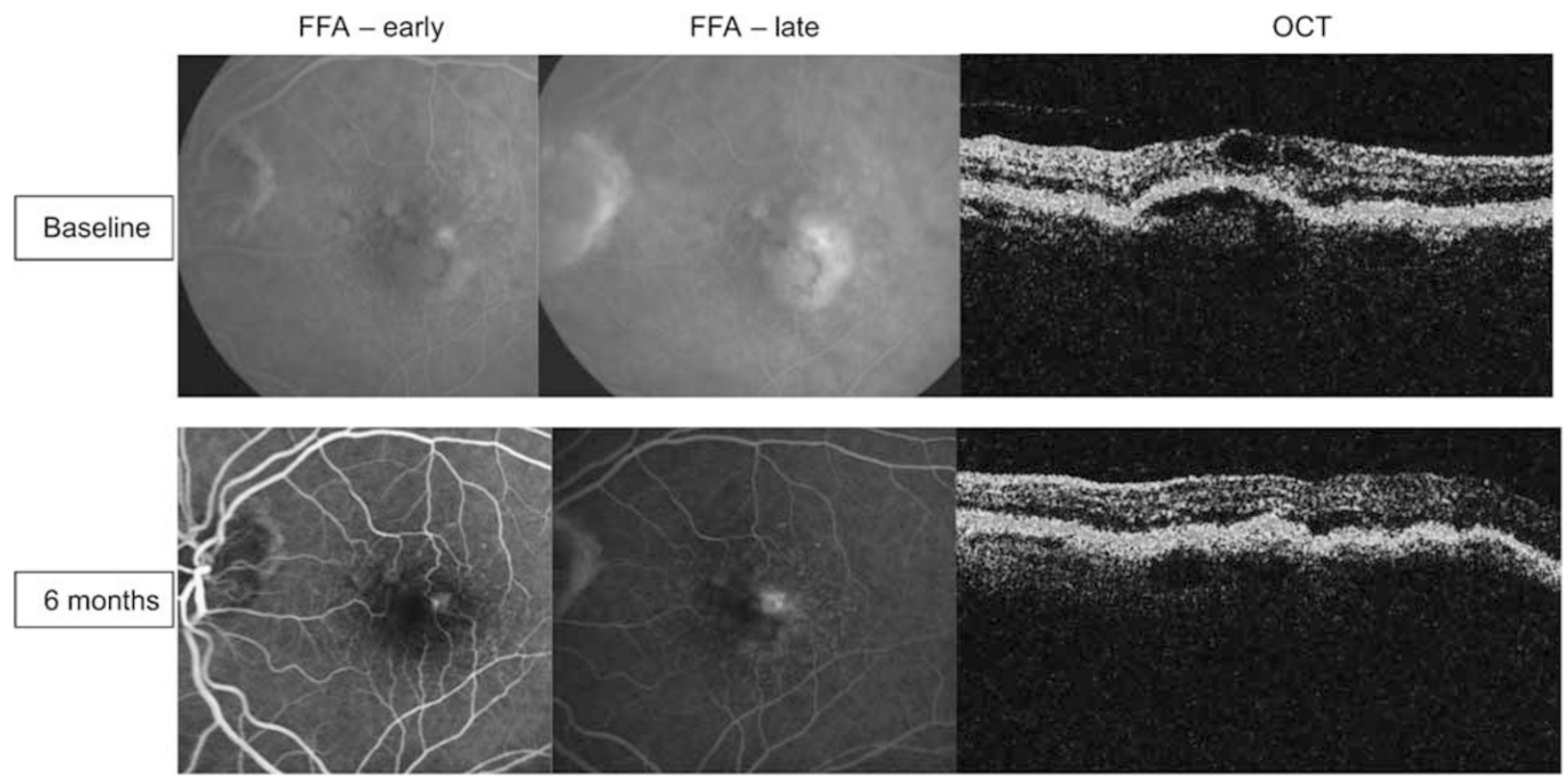

Figure 1 Stage 2 RAP with serous pigment epithelial detachment. 
patients. Five patients (33\%) remained within 5 letters of baseline, $2(13 \%)$ gained $>5$ letters, $8(53 \%)$ lost $>5$ letters of whom $2(13 \%)$ lost $>15$ letters.

Mean OCT CFT $(n=13)$ at baseline was $325 \pm 123 \mu \mathrm{m}$, $343 \pm 130 \mu \mathrm{m}$ at 12 weeks, and $321 \pm 115 \mu \mathrm{m}$ at 24 weeks. At 24 weeks, the difference was not statistically significant ( $P=0.9$ paired $t$-test). In six patients CFT increased by a mean of $77 \mu \mathrm{m}$ (range 20-129); in seven patients, CFT decreased by mean of $74 \mu \mathrm{m}$ (range -16 to -205). OCT confirmed a PED in 12 cases. At 24 weeks, the PED height was reduced in 10 of these cases.

Review of the fluorescein angiograms showed that in 13 out of 15 cases the lesion showed signs of persistent leakage at 24 weeks. In the remaining two cases the lesion did not show any signs of active leakage at 24 weeks. In two cases the GLD of the active lesion increased by 1.03 and $1.25 \mathrm{~mm}$. In the remainder there was a small reduction at 24 weeks (mean $-0.44 \mathrm{~mm}$ ). The difference did not reach statistical significance $(P=0.5)$.

No adverse reactions occurred during the study period.

\section{Sample cases}

Two cases are presented, one illustrating a good response and also more detail on the patient with a poor response and change of treatment. Most lesions remained stable.
Patient no. 1 (Figure 1): an 80-year-old female presented with recent reduction of vision to 6/18 (63 letters) with diagnosis of RAP. Baseline FA and OCT showed a RAP complex and a serous PED with baseline CFT of $258 \mu \mathrm{m}$. Six months after injection there was minimal residual leakage on FA and CFT was $242 \mu \mathrm{m}$. BCVA was a little better (68 letters).

Patient no. 16 (Figure 2): a 75-year-old female with a 2-month history of reduction in vision in her left eye. The fellow eye had mature fibrosed CNV. Baseline BCVA was 63 ETDRS letters. FFA and OCT showed RAP vessels and a large FPED with baseline CFT $399 \mu \mathrm{m}$.

At 6 weeks, vision had dropped to 39 letters and area involved by FPED enlarged. CFT had increased to $863 \mu \mathrm{m}$. The treatment was switched to PDT and IVTA. At 6 months from baseline, vision had improved again to 61 letters, CFT reduced to $238 \mu \mathrm{m}$.

\section{Discussion}

We report the early response to intravitreal pegaptanib therapy in RAP, an uncommon variant of AMD. Eighty seven per cent of cases maintained vision within 15 letters of baseline with $13 \%$ gaining $\geqslant 5$ and $53 \%$ losing $\geqslant 5$. There was variability in response to treatment as measured by CFT on OCT with roughly equal numbers experiencing increased and decreased thickness. The height of the PED reduced in the majority of cases. There
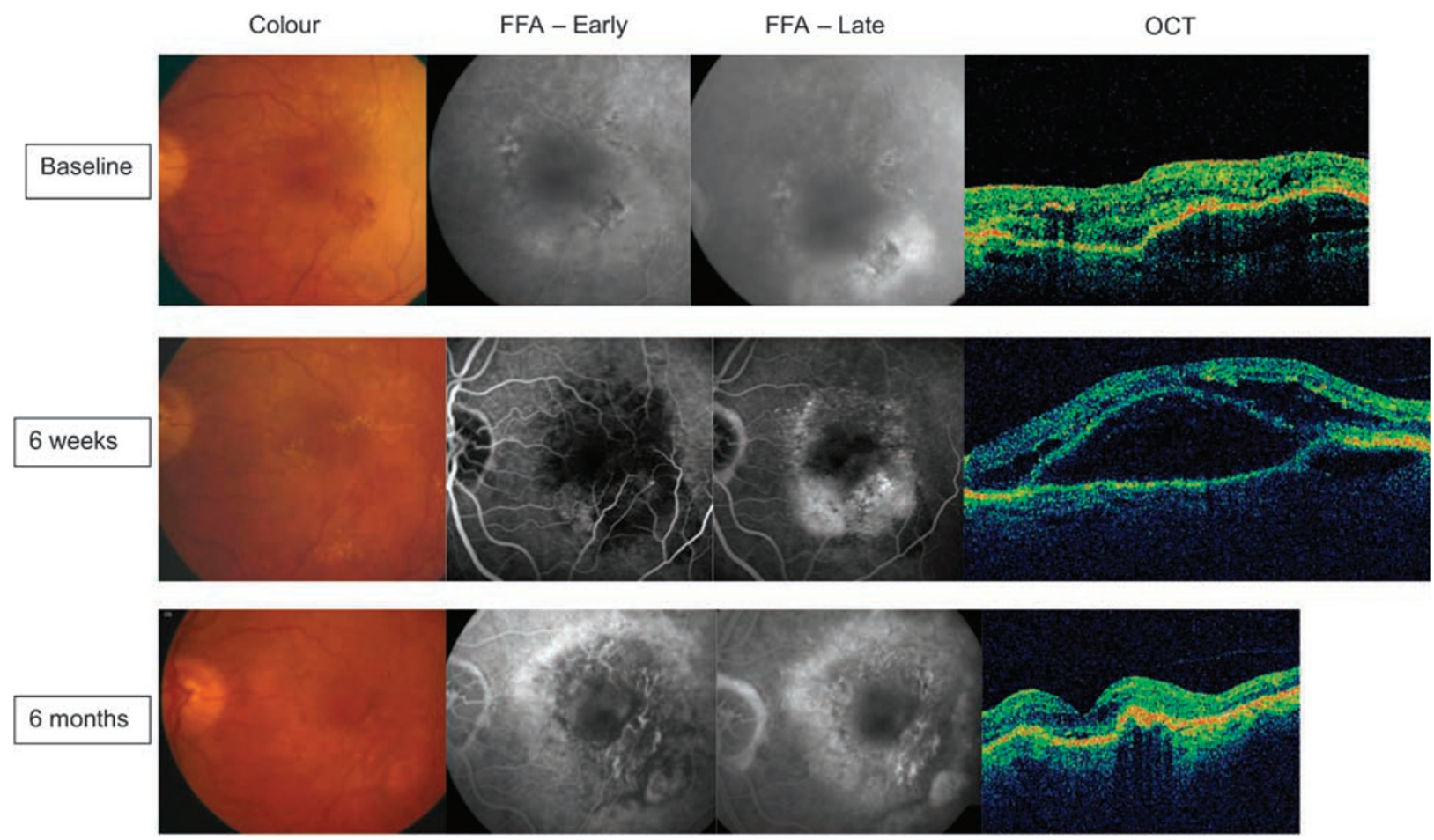

Figure 2 Stage 3 RAP with fibrovascular and serous pigment epithelial detachment. 
Table 2 Three-month visual acuity outcomes in studies of anti-VEGF for RAP

\begin{tabular}{|c|c|c|c|c|c|c|c|}
\hline & No. & $\begin{array}{c}\text { RAP } \\
\text { stage } 1\end{array}$ & $\begin{array}{c}\text { RAP } \\
\text { stage } 2\end{array}$ & $\begin{array}{c}\text { RAP } \\
\text { stage } 3\end{array}$ & $\begin{array}{c}\text { Visual loss } \geqslant 3 \\
\text { Snellen lines }(\%)\end{array}$ & $\begin{array}{l}\text { Visual } \\
\text { improvement (\%) }\end{array}$ & $\begin{array}{c}\text { Total stabilization (within } \\
3 \text { Snellen lines) or } \\
\text { improvement }(\%)\end{array}$ \\
\hline $\begin{array}{l}\text { Bevacizumab } \\
\text { (Joeres et } a l^{22} \text { ) }\end{array}$ & 16 & 0 & $16(\mathrm{n}$ & $\begin{array}{l}\text { sified } \\
\text { ly) }\end{array}$ & 0 & $\begin{array}{l}50 \text { (gain } \geqslant 2 \\
\text { Snellen lines) }\end{array}$ & 100 \\
\hline $\begin{array}{l}\text { Bevacizumab } \\
\text { (Meyerle } \text { et } a l^{21} \text { ) }\end{array}$ & 23 & 11 & 10 & 2 & 5.9 & $\begin{array}{l}29.4 \text { (gain } \geqslant 3 \\
\text { Snellen lines) }\end{array}$ & 94.1 \\
\hline $\begin{array}{l}\text { Pegaptanib } \\
\text { (current paper) }\end{array}$ & 16 & 0 & 1 & 15 & 18.8 & $\begin{array}{l}6.3 \text { (gain } \geqslant 3 \\
\text { Snellen lines) }\end{array}$ & 81.3 \\
\hline
\end{tabular}

was some reduction of leakage on FA. Complete resolution of leakage was achieved in only two patients after 24 weeks of treatment. There was a statistically significant trend toward a small reduction of five letters in BCVA but no significant change on OCT CFT.

In future, intravitreal anti-VEGF agents may become the most common therapy for neovascular AMD. Their usage in the context of RAP requires more study, preferably of large numbers, but this is likely to prove difficult due to the small numbers of cases seen even in large treatment centres, such as ours. RAP lesions, where identified, have been excluded from the large, multicentre, randomised controlled clinical trials of pegaptanib and ranibizumab.

At the time of writing, two case series have reported the use of intravitreal bevacizumab and the possible beneficial effects at 3-month review. In the case series reported by Meyerle et al, out of 17 patients, vision loss was reported in only one case and five eyes (29.4\%) had better acuity. There was a significant reduction in mean CFT. Change in angiographic leakage was not reported..$^{21}$ Joeres et $\mathrm{l}^{22}$ studied 16 patients, eight eyes (50\%) gained $\geqslant 2$ lines visual acuity from baseline to month 3; none of the eyes lost $\geqslant 2$ lines. There was a significant reduction in central macular thickness but no morphological change in the feeder vessel and closure was not achieved in any case.

Comparison of these case series with our patients shows a high level of stabilisation of vision at 3 months with both drugs but pegaptanib does not appear to show the same level of visual improvement (Table 2). Both series of bevacizumab also report significant reduction in mean CFT. This may indicate a higher degree of efficacy for bevacizumab but the patient characteristics are not comparable. In our series, only one case was stage 2 RAP, the rest stage 3 . In Meyerle et $a^{21}$ case series, $48 \%$ of patients had stage 1 disease and only $9 \%$ stage 3 . Joeres et al stated that 'no differentiation is made between stage 2 and stage 3 lesions' so the series may have been a mix of stage 2 and 3 disease. Previous reports indicate that treatment of RAP at earlier stages may lead to better anatomical and functional outcomes; when the vascular complex is well established, anatomical closure is difficult to achieve. ${ }^{23}$

In conclusion, intravitreal anti-VEGF treatment with pegaptanib appears to have an effect on vision and CFT in patients with RAP. Against the background of a generally aggressive natural history, treatment appears to maintain function at 6 months in the majority of patients, although the effect appears to be limited and somewhat variable. Long-term follow-up at 12 and 24 months would show if this effect is maintained. Large randomized, controlled trials are also required to establish optimum treatment but may prove difficult to organise.

\section{Acknowledgements}

We are grateful for the assistance of Ms Claire Kelly and the staff of The Clinical Eye Research Centre, St Paul's Eye Unit, Liverpool. St Paul's Eye Unit has received departmental commercial funding as a clinical centre in trials of verteporfin, pegaptanib, and ranibizumab. $\mathrm{HH}$ and $\mathrm{SPH}$ have received support for travel and conference attendance.

\section{References}

1 Slakter JS, Yannuzzi LA, Schneider U, Sorenson JA, Ciardella A, Guyer DR et al Retinal choroidal anastomoses and occult choroidal neovascularization in age-related macular degeneration. Ophthalmology 2000; 107(4): 742-753; discussion 753-4.

2 Yannuzzi LA, Negrao S, Iida T, Carvalho C, RodriguezColeman H, Slakter J et al Retinal angiomatous proliferation in age-related macular degeneration. Retina 2001; 21(5): 416-434.

3 Krebs I, Stolba U, Glittenberg C, Seyeddain O, Benesch T, Binder S. Prognosis of untreated occult choroidal neovascularization. Graefes Arch Clin Exp Ophthalmol 2007; 245(3): 376-384. 
4 Gross NE, Aizman A, Brucker A, Klancnik Jr JM, Yannuzzi LA. Nature and risk of neovascularization in the fellow eye of patients with unilateral retinal angiomatous proliferation. Retina 2005; 25(6): 713-718.

5 Johnson TM, Glaser BM. Focal laser ablation of retinal angiomatous proliferation. Retina 2006; 26(7): 765-772. erratum appears in Retina 2007; (2):263.

6 Slakter JS, Yannuzzi LA, Schneider U, Sorenson JA, Ciardella A, Guyer DR et al Retinal choroidal anastomoses and occult choroidal neovascularization in age-related macular degeneration. Ophthalmology 2000; 107(4): 742-753.

7 Borrillo JL, Sivalingam A, Martidis A, Federman JL. Surgical ablation of retinal angiomatous proliferation. Arch Ophthalmol 2003; 121(4): 558-561.

8 Shiragami C, Iida T, Nagayama D, Baba T, Shiraga F. Recurrence after surgical ablation for retinal angiomatous proliferation. Retina 2007; 27(2): 198-203.

9 Klais CM, Eandi CM, Ober MD, Sorenson JA, Sadeghi SN, Freund $\mathrm{KB}$ et al Anecortave acetate treatment for retinal angiomatous proliferation: a pilot study. Retina 2006; 26(7): 773-779.

10 Boscia F, Furino C, Sborgia L, Reibaldi M, Sborgia C. Photodynamic therapy for retinal angiomatous proliferations and pigment epithelium detachment. Am J Ophthalmol 2004; 138(6): 1077-1079.

11 Freund KB, Klais CM, Eandi CM, Ober MD, Goldberg DE, Sorenson JA et al Sequenced combined intravitreal triamcinolone and indocyanine green angiography-guided photodynamic therapy for retinal angiomatous proliferation. Arch Ophthalmol 2006; 124(4): 487-492.

12 van de Moere A, Kak R, Sandhu SS, Talks SJ. Anatomical and visual outcome of retinal angiomatous proliferation treated with photodynamic therapy and intravitreal triamcinolone. Am J Ophthalmol 2007; 143(4): 701-704.

13 Krebs I, Binder S, Stolba U. A new treatment regimen in combined intravitreal injection of triamcinolone acetonide and photodynamic therapy. Graefes Arch Clin Exp Ophthalmol 2006; 244(7): 863-867. e-pub ahead of print 6 December 2005.
14 Smithen LM, Ober MD, Maranan L, Spaide RF. Intravitreal triamcinolone acetonide and intraocular pressure. Am J Ophthalmol 2004; 138(5): 740-743.

15 Jonas JB, Sauder G, Budde WM, Spandau UH, Kamppeter BA, Harder B. Triamcinolone acetonide-induced ocular hypertension. J Ocul Pharmacol Ther 2006; 22(4): 247-250.

16 Gragoudas ES, Adamis AP, Cunningham ET, Feinsod M, Guyer DR, for the VEGF Inhibition Study in Ocular Neovascularization Clinical Trial Group. Pegaptanib for Neovascular Age-Related Macular Degeneration. $N$ Engl J Med 2004; 351: 2805-2816.

17 Brown DM, Kaiser PK, Michels M, Soubrane G, Heier JS, Kim RY, et al, ANCHOR Study Group. Ranibizumab vs verteporfin for neovascular age-related macular degeneration. N Engl J Med 2006; 355(14): 1432-1444.

18 Rosenfeld PJ, Brown DM, Heier JS, Boyer DS, Kaiser PK, Chung CY, et al, MARINA Study Group. Ranibizumab for neovascular age-related macular degeneration. $N$ Engl J Med 2006; 355(14): 1419-1431.

19 Avery RL, Pieramici DJ, Rabena MD, Castellarin AA, Nasir MA, Giust MJ. Intravitreal bevacizumab (Avastin) for neovascular age-related macular degeneration. Ophthalmology 2006; 113: 363-372.

20 Spaide RF, Laud K, Fine HF, Klancnik Jr JM, Meyerle CB, Yannuzzi LA et al Intravitreal bevacizumab treatment of choroidal neovascularization secondary to age-related macular degeneration. Retina 2006; 26: 383-390.

21 Meyerle CB, Freund KB, Iturralde D, Spaide RF, Sorenson JA, Slakter JS et al Intravitreal bevacizumab (Avastin) for retinal angiomatous proliferation. Retina 2007; 27(4): 451-457.

22 Joeres S, Heussen FM, Treziak T, Bopp S, Joussen AM. Bevacizumab (Avastin) treatment in patients with retinal angiomatous proliferation. Graefes Arch Clin Exp Ophthalmol 2007; 245(11): 1597-1602.

23 Bottoni F, Massacesi A, Cigada M, Viola F, Musicco I, Staurenghi G. Treatment of retinal angiomatous proliferation in age-related macular degeneration: a series of 104 cases of retinal angiomatous proliferation. Arch Ophthalmol 2005; 123(12): 1644-1650. 